\title{
Chloropid flies (Diptera, Chloropidae) associated with pitcher plants in North America
}

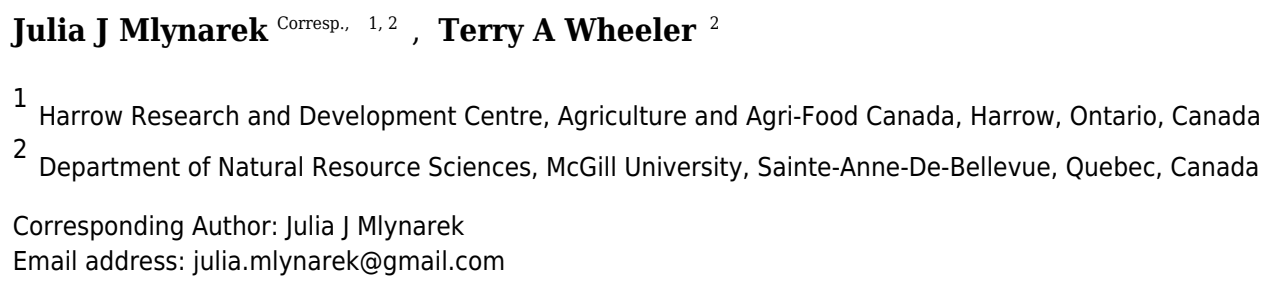

We review the taxonomy and ecology of Chloropidae (Diptera) associated with pitcher plants (Sarraceniaceae) in North America. Tricimba wheeleri Mlynarek sp. $\mathbf{n}$. is described from the pitchers of Sarracenia alata Alph.Wood and S. leucophylla Raf. in the southeastern United States (Alabama, Mississippi). Aphanotrigonum darlingtoniae (Jones) associated with Darlingtonia californica Torr. in northern California is redescribed, including the first description of male genitalic characters. A lectotype is designated for $A$. darlingtoniae. Published records of other species of Tricimba Lioy in pitcher plants in North America are considered accidental or facultative occurrences; published records of Aphanotrigonum Duda as pitcher plant associates in eastern North America are probably errors in identification. 
1 Chloropid flies (Diptera, Chloropidae) associated with pitcher plants in North America 2

3 Julia J. Mlynarek ${ }^{1,2^{*}}$ and Terry A. Wheeler ${ }^{1 \dagger}$

4

5 'Department of Natural Resource Sciences, McGill University, Ste-Anne-de-Bellevue, QC, 6 Canada

$7{ }^{2}$ Current address: Agriculture and Agri-Food Canada, Harrow Research and Development

8 Centre, Harrow, ON, Canada

9 *corresponding author

$10{ }^{\dagger}$ Deceased 


\section{Abstract}

12 We review the taxonomy and ecology of Chloropidae (Diptera) associated with pitcher plants

13 (Sarraceniaceae) in North America. Tricimba wheeleri Mlynarek sp. n. is described from the

14 pitchers of Sarracenia alata Alph.Wood and S. leucophylla Raf. in the southeastern United

15 States (Alabama, Mississippi). Aphanotrigonum darlingtoniae (Jones) associated with

16 Darlingtonia californica Torr. in northern California is redescribed, including the first

17 description of male genitalic characters. A lectotype is designated for A. darlingtoniae. Published

18 records of other species of Tricimba Lioy in pitcher plants in North America are considered

19 accidental or facultative occurrences; published records of Aphanotrigonum Duda as pitcher

20 plant associates in eastern North America are probably errors in identification. 


\section{Introduction}

24 There are two very different ways in which insects can associate with pitcher plants

25 (Sarraceniaceae): they can die in the modified, pitcher-shaped leaves and become a source of

26 nutrients for the plant; or they can live in the pitchers and become active partners in a fascinating

27 ecosystem. Several families of Diptera in North America include pitcher plant associated

28 species: ten species of Sarcophagidae (Dahlem and Naczi 2006) and one or two species each of

29 Culicidae, Chironomidae, Sciaridae, and Chloropidae (Jones 1916, 1920, Szerlip 1975, Folkerts

30 1999, Dahlem and Naczi 2006).

32 Jones (1916) described a new species of Chloropidae, Botanobia darlingtoniae Jones (transferred

33 to Aphanotrigonum Duda by Sabrosky (1965)) from specimens reared from pitchers of

34 Darlingtonia californica Torr. in California, but that fly has not been documented in association

35 with pitcher plants since its original description. There are records of a second, undescribed

36 species of Aphanotrigonum Duda from multiple species of Sarracenia L. in eastern North

37 America (Folkerts 1999). However, based on examination of specimens collected from

38 Sarracenia spp. in eastern North America, the eastern chloropids are not congeneric with $A$.

39 darlingtoniae but actually belong to Tricimba Lioy, an externally similar, but distantly related, 40 genus.

42 In this paper, we revise the two species of Chloropidae known to be associated with pitcher

43 plants in North America, with a redescription of $A$. darlingtoniae from the western United States

44 and a description of Tricimba wheeleri Mlynarek sp. n. from the southeastern United States. 
45 Adults of $T$. wheeleri have unusual modifications of the tarsi not known in other species of

46 Tricimba, possibly associated with locomotion by adult flies inside pitchers of their host plants.

48 Methods

50 Specimens studied are deposited in the following collections: Lyman Entomological Museum,

51 McGill University, Ste-Anne-de-Bellevue, Quebec, Canada (LEMQ); Personal collection of

52 Robert F.C. Naczi (RFCN); United States National Museum of Natural History, Smithsonian

53 Institution, Washington, DC, USA (USNM).

54 Two specimens of $A$. darlingtoniae from LEMQ were submitted to the Canadian Centre for

55 DNA Barcoding (University of Guelph, Guelph, Ontario, Canada) for sequencing of the $658 \mathrm{bp}$

56 DNA barcode region of the mitochondrial gene $\mathrm{CO} 1$.

57 Fieldwork in California was facilitated by a California State Park Scientific Collecting Permit

58 (2009) number 9-0735 issued to S.D. Gaimari (CSCA).

59 Male genitalia were prepared by removing the abdomen of pinned specimens and clearing them

60 in $85 \%$ lactic acid heated in a microwave oven for 1-2 periods of 10 seconds, separated by a 1

61 minute cooling period.

62 Morphological terms follow Cumming and Wood (2009).

63 The electronic version of this article in Portable Document Format (PDF) will represent a

64 published work according to the International Commission on Zoological Nomenclature (ICZN),

65 and hence the new names contained in the electronic version are effectively published under that

66 Code from the electronic edition alone. This published work and the nomenclatural acts it

67 contains have been registered in ZooBank, the online registration system for the ICZN. The 
68 ZooBank LSIDs (Life Science Identifiers) can be resolved and the associated information viewed

69 through any standard web browser by appending the LSID to the prefix http://zoobank.org/. The

70 LSID for this publication is: urn:lsid:zoobank.org:pub:67933A14-78D1-4A3B-AC17-

71 B00951574F39. The online version of this work is archived and available from the following

72 digital repositories: PeerJ, PubMed Central and CLOCKSS. 


\section{Results and Discussion}

\section{Aphanotrigonum darlingtoniae (Jones)}

77 Botanobia darlingtoniae Jones, 1916: 389. Type locality: Mount Eddy, near Sisson, Siskiyou

78 County, California (see Comments).

79 Aphanotrigonum darlingtoniae: Sabrosky, 1965: 785.

80

81 Type material. Lectotype (here designated): M labelled: "Sisson, Cal./Bred. F. M. Jones./VIII-5-

82 1915”; “m\# TYPE”; “Type No./20318/U.S.N.M.”; “Oscinella/darlingtoniae/Type.) Jones”

83 (USNM).

84 Paralectotypes F: same data as lectotype except "VIII-15-1915"; "f\# TYPE"; "Allotype

85 No./20318/U.S.N.M.” (USNM). F: same except: "VII-29-1916” [probably error for 1915];

86 'Botanobia/darlingtoniae/Type ] Jones”; red square blank label] (USNM) (See Remarks).

Other material examined. USA: CA: Siskiyou Co. 6km NW Mt Eddy, Forest Road 17 (41.3573, $\left.89-122.5409^{\circ}\right), 2060 \mathrm{~m}$, sweep wet Darlingtonia meadow, 08.vi.2009. J. Mlynarek (5M, 6F,

90 LEMQ), same data except T.A. Wheeler (3M, 1F, LEMQ).

91

92 Diagnosis. (Figs. 1-2) Aphanotrigonum darlingtoniae can be distinguished from the other

93 described Nearctic species of the genus (A. scabrum (Aldrich), A. trilineatum (Meigen)) by the

94 combination of: dark bristles on gena, three brown stripes on scutum in the shape of a lyre, sides

95 of scutellum also brown (uniformly gray in paratypes of scabrum from Treesbank), interfrontal 
96 setulae are darker, more contrasting with frons in darlingtoniae and distinction between gray

97 triangle and yellow anterior part of frons seems less clear in darlingtoniae than in scabrum.

99 Description (Fig 1). Total length 2.3-3.1 mm . Overall colour black, frontal triangle brown-

100 black, pollinose, wide, 2/3 length of frons; ocellar tubercle black, pollinose; frons yellow to

101 brown, wider than long; cephalic setae dark, strong but short, frontal-orbital bristles short, black

102 and convergent, two rows of interfrontal setulae inside the margin of frontal triangle; gena wide,

103 anterodorsally yellow, ventrally black, 0.3-0.4 times eye height; eye bare; postgena black,

104 pubescent and 1/5 width of eye; face yellow to brown; scape and pedicel yellow, first

105 flagellomere oval, 1.25-1.35 higher than long, first segment of arista black, rest of arista black,

106 slender and 2-2.5 times width of first flagellomere; palpus yellow, proboscis brown, clypeus

107 black and shiny.

109 Scutum black with three brown dorsal lines, grey pollinosity, 1.2-1.4 times wider than long,

110 pronotum black, shiny, thin; scutellum black, pollinose, 1.4-1.5 times as wide as long, apical

111 scutellar bristles black and stronger than surrounding setae, on very small tubercles; thoracic

112 pleura pollinose; dorsal margin of anepimeron and lateral region of postscutellum pollinose.

113 Femur black, tibiae yellow with thick black band, metatarsi yellow; femoral organ absent; tibial

114 organ present, black, 0.3 length of tibia. Ratio of costal sectors $\mathrm{C} 1: \mathrm{C} 2: \mathrm{C} 3: \mathrm{C} 4$ on wing

$115 \quad 1: 1.3: 1: 0.5$.

116

117 Abdomen black, pollinose, longer than thorax; syntergite 1+2 same length as remaining tergites. 
119 Male postabdomen (Fig 2): small; epandrium in lateral view 1.4 times higher than wide, in

120 posterior view 1.5 times wider than high, setae sparse covering posterior portion of epandrium;

121 surstylus 0.75 times as high as epandrium, parallel sided with a rounded tip, setae short and

122 sparse; cercus square in posterior view, triangular in lateral view, separated by a small evenly

123 rounded arc, bristles short with one long bristle on the posteromedial edge; distiphallus not well

124 sclerotized.

125

126 Molecular sequence data. DNA barcodes (658 bp of CO1) for two LEMQ specimens of $A$.

127 darlingtoniae are available on the Barcode of Life Database (boldsystems.org), (BOLD

128 accession numbers: CCDB-21328-A12/LYMAA1247-14; CCDB-21328-B01/LYMAA1248-14).

130 Remarks. Jones (1916) recorded the type locality as "Mount Eddy, near Sisson, Siskiyou

131 County, California". Sisson is the former name for the town of Mount Shasta. There are several 132 populations of Darlingtonia californica in the area surrounding Mount Eddy, west of Mount

133 Shasta, so it is impossible to determine precisely the type locality. The second female type

134 specimen is not labelled as a type either but is assumed and now designated as a paralectotype,

135 because the emergence data matches that given in the original publication. In addition, the 136 determination label is in Jones' handwriting.

137 Our 2009 collections occurred early in the season (Fig 3). Darlingtonia pitchers were

138 small and pale green, in contrast to the previous year's dark pitchers. There were still patches of 139 snow in the open forest near the collecting site and other herbaceous plants in the vicinity were

140 early in their annual development. Sampling was non-destructive; we swept just above the

141 substrate adjacent to the developing pitchers and over the debris of the previous year's growth. 
142 Jones (1916) based his description of A. darlingtoniae on adult specimens reared from pitchers

143 of D. californica, but our collecting suggests that adults can live outside pitchers and, given the

144 small size of new pitchers, the adult flies may overwinter in the substrate outside the pitchers as

145 was suggested by Jones (1916). Jones (1916) also described the immature stages of $A$.

146 darlingtoniae, which were subsequently reviewed by Johannsen (1935).

147 Our collected specimens of A. darlingtoniae from California clusters in the same BIN as

148 Aphanotrigonum trilineatum from Alberta, British Columbia, and New Brunswick. We

149 morphologically compared the two species to confirm the validity of $A$. darlingtoniae. We also

150 dissected and compared male genitalia. Even though they share the same BIN and molecular

151 barcode, Aphanotrigonum darlingtoniae is morphologically distinct from A. trilineatum

152 supporting the validity of both species.

153

154 Tricimba wheeleri Mlynarek new species

155 LSID: urn:1sid:zoobank.org:act:C9CC48AD-AE7A-49DB-B849-2C64B6C5E812

156 Type locality. USA: Alabama: Mobile County, $5 \mathrm{mi}$ W of Citronelle.

157 Type material. Holotype M: USA: Alabama: Mobile County, $5 \mathrm{mi} \mathrm{W}$ of Citronelle, $31.08^{\circ} \mathrm{N}$

158 88.3 W 2.viii.1994, R.F.C. Naczi, Ex. Sarracenia leucophylla (LEMQ). Paratypes: 24 M, 31 F:

159 same as holotype; 1 F: Theodore, 21.vi.1915, F.M. Jones (USNM); Mississippi: 14 M, 22 F:

160 Stone County, 9mi E of Wiggins, $30.8^{\circ} \mathrm{N} 88.9^{\circ} \mathrm{W}$ 1.viii.1994, R.F.C. Naczi, Ex Sarracenia alata.

161 (LEMQ).

162

163 Other material (not examined). USA. Alabama: Baldwin Co., 0.9 mi NNE of Perdido,

$16431.0206^{\circ} \mathrm{N}, 87.6234^{\circ} \mathrm{W}, 28$ April 1988; R. F. C. Naczi, adults collected from inside upper

165 portions of Sarracenia leucophylla pitchers. (2M 3F, RFCN) Florida: Okaloosa Co., 3 mi S of 
166 Crestview, $30.6990^{\circ} \mathrm{N}, 86.5745^{\circ} \mathrm{W}, 19$ Aug. 1984 ; R. F. C. Naczi, adults collected from inside

167 upper portions of Sarracenia leucophylla pitchers. (3M, RFCN)

168

169 Diagnosis (Figs 4-6). Tricimba wheeleri can be distinguished from the other described Nearctic

170 species of the genus by the combination of: shallowly incised scutal lines, and heavily

171 microtomentose gray scutum, expanded distal tarsal segments (Fig 6).

172

173 Description (Fig 4, 6). Total length 1.7-2.7 mm. Overall colour brown to black, frontal triangle

174 black, pollinose, 0.4-0.5 times length of frons; ocellar tubercle black, pollinose; frons yellow

175 anteriorly, darkening posteriorly until black, size 1.2-1.3 times longer than wide; cephalic setae

176 slender and pale, frontal-orbital bristles even, interfrontal setulae on margin of frontal triangle;

177 gena yellow, pollinose, 0.2-0.3 times eye height; eye bare; postgena black, pollinose and thin;

178 face brown, as high as wide; scape and pedicel yellow, first flagellomere yellow

179 proximoventrally darkening distodorsally, negligibly higher than wide, first segment of arista

180 yellow to brown, rest of arista slender, brown, sparsely hairy and twice as long as first antennal

181 segment; palpus and proboscis yellow, clypeus brown.

182

183 Scutum black, pollinose, with three weakly incised dorsal lines along the dorsocentral and

184 acrostichal lines, covered in fine yellow hairs, 1-1.2 times longer than wide, pronotum black and

185 shiny; postpronotum brown to black; scutellum yellow, round, 1.6-1.8 times as wide as long,

186 apical scutellar bristles black and a lot longer than surrounding setae, on small tubercles; thoracic

187 pleurites brown to black, pollinose; dorsal margin of anepimeron and lateral region of

188 postscutellum pollinose. Legs brown, joints sometimes paler; femoral organ absent; tibial organ 
189 present, yellow to black, large, 0.3 length of tibia. Distal tarsal segments expanded, pulvilli

190 enlarged and long tarsal claws. Ratio of costal sectors C1:C2:C3:C4 on wing 1:0.95:0.6:0.5.

191

192 Abdomen black, pollinose, longer than thorax; syntergite 1+2 same length as remaining tergites.

194 Male postabdomen (Fig 5): large; epandrium in lateral view as high as wide, in posterior view

1951.4 times as wide as high, setae densely covering posterior end of epandrium; surstylus 0.8 times

196 height of epandrium, setae short and sparsely covering entire surstylus; cercus large, parallel

197 sided and rounded apically, separated by small evenly rounded arc, bristles short, covering entire 198 cercus; distiphallus small and poorly sclerotized.

199

200 Etymology. The species name is a genitive patronym in honour of Terry A. Wheeler, the co-

201 author of this manuscript who passed away during the final stages of this project and contributed

202 much to our knowledge of the Chloropidae. He always said that "this is probably the last species 203 of insect that is associated with North American pitcher plants that needs to be described, how 204 fitting it should be a chloropid”.

205

206 Remarks. In addition to collecting a single paratype, F.M. Jones made notes on additional 207 specimens from Alabama, North Carolina, and South Carolina apparently belonging to this 208 species. Unpublished sketches in the F.M. Jones archives, deposited in the Peabody Museum of 209 Natural History, Yale University, New Haven, CT, USA

210 (http://harvardforest.fas.harvard.edu/botanobia-darlingtoniae), of specimens collected from 
211 Sarracenia drummondii (= S. leucophylla), S. flava, S. minor and S. rubra illustrate the expanded

212 distal tarsal segments, long tarsal claws, and expanded pulvilli.

213

214 The type specimens from Sarracenia leucophylla and S. alata were collected as adults from

215 inside the upper portion of the pitchers (RFC Naczi, pers. comm.)

216

217 The tarsal modifications are not present in other Nearctic Tricimba species and may be an

218 adaptation for walking on the surface of the debris inside pitchers (Fig 6).

219

220 Folkerts (1999) recorded an undescribed species of "Aphanotrigonum" from Sarracenia species

221 in the eastern United States and that record has been repeated by others (e.g., Dahlem and Naczi

222 2006). Although we have not seen vouchers of the specimens referred to by Folkerts, that record

223 likely refers to Tricimba wheeleri. Folkerts (1999) named, but never published, the species from

224 Sarracenia species in the eastern United States as the sister species to Aphanotrigonum

225 darlingtoniae; however, we do not consider it the description as a valid designation of the

226 species and this record appears to be an error based on the conflation of Aphanotrigonum with

227 Bradysia macfarlanei (Jones) (Diptera: Sciaridae), another known inhabitant of Sarracenia

228 pitchers in the southeastern United States. There is, obviously, no evidence of a sister group

229 relationship between the western and eastern pitcher plant Chloropidae, given that they belong to 230 different genera.

231

232 Tricimba sp. 
233 Material examined. USA: California: Del Norte Co., Gasquet, 31.iii.1986, emerged 14.iv.1986,

234 D.W. Nielsen, ex larvae coll. in pitchers of Darlingtonia californica (1M, USNM); same data

235 except emerged 23.iv.1986 (1F, USNM).

236 Remarks. Two specimens identified by Nielsen (1990) as an undescribed species of

237 Nartshukiella $(=$ Tricimba) $\mathrm{nr}$. melancholica (Becker) were reared from a single Darlingtonia 238 californica pitcher (of a total of 124 pitchers sampled) in Del Norte County, California. At the

239 time of collection, flies were sent to C.W. Sabrosky (USNM) for identification and are still

240 deposited in USNM. The specimens are a typical Tricimba melancholica group species. The tarsi

241 are not modified as in T. wheeleri (Fig 6). Given that only two specimens were reared in the

242 course of a large-scale study of Darlingtonia insect associates, this may have been an

243 opportunistic colonization of a single pitcher plant by a generalist saprophagous species. The

244 association should be considered facultative, and more research into the natural history of this as

245 yet undescribed species is necessary.

246 Conclusion

247 There are two species, Aphanotrigonum darlingtoniae and Tricimba wheeleri (described here),

248 which live in the pitchers of North American pitcher plants and have apparently become active

249 partners in a fascinating ecosystem. Aphanotrigonum is a widespread genus with a Holarctic,

250 New Zealand and Oriental distribution (Nartshuk 2012). It is less common than Tricimba, which

251 is a species-rich genus present in all biogeographical regions, except Antarctica (Nartshuk 2012).

252 Members of these genera are mostly saprophagous although there are a few predatory and

253 parasitic species in Tricimba (Nartshuk 2014). It is unknown whether any of the other species of

254 Aphanotrigonum or Tricimba are closely associated with any particular plant or animal species

255 like $A$. darlingtoniae is to Darlingtonia californica and $T$. wheeleri is to Sarracenia pitcher 
256 plants. Revisions of both genera, including their ecological habits and phylogenies, would help

257 understand the evolution of specialization in these two species associated with pitcher plants and 258 achieve better appreciation of chloropid diversity. 


\section{Acknowledgments}

260 Fieldwork in California was facilitated by Steve Gaimari and Peter Kerr (California Department

261 of Food and Agriculture). Rob Naczi (New York Botanical Garden) provided type specimens

262 and ecological information on Tricimba wheeleri. Aaron Ellison (Harvard Forest) connected us

263 with the F. M. Jones archives and Steve Marshall (University of Guelph) alerted us to the Szerlip

264 (1975) paper. Norm Woodley (USNM) arranged access to the USNM collection. Staff at the

265 Biodiversity Institute of Ontario, especially Valérie Lévesque-Beaudin, collaborated on the DNA

266 barcoding of $A$. darlingtoniae. Stephen Heard made helpful comments on the manuscript. 


\section{References}

268 Cumming JM \& Wood DM (2009) Adult morphology and terminology. In: Brown BV, Borkent

A, Cumming JM, Wood DM, Woodley NE \& Zumbado MA (Eds.): Manual of Central

270 American Diptera Vol. 1. National Research Council Press, Ottawa, pp. 9-502.

271

Dahlem GA, Naczi RF (2006) Flesh flies (Diptera: Sarcophagidae) associated with North

272 American pitcher plants (Sarraceniaceae), with descriptions of three new species. Annals

273 of the Entomological Society of America 99: 218-240.

274

Folkerts D (1999) Pitcher plant wetlands of the southeastern United States. Arthropod associates.

275 In: Batzer DP, Rader RB, Wissinger SA (Eds) Invertebrates in freshwater wetlands of

276

277 North America: ecology and management. Wiley, New York, 247-275.

Johannsen OA (1935) Aquatic Diptera. Part II. Orthorrhapha-Brachycera and Cyclorrhapha.

278 Cornell University Agricultural Experiment Station Memoir 177: 1-62.

279

280

281

282

283

284

285

286

287

288

289

290

291

292

293

294

Jones FM (1916) Two insect associates of the California pitcher-plant, Darlingtonia californica (Dipt.). Entomological News 27: 385-392.

Jones FM (1920) Another pitcher-plant insect (Diptera, Sciaridae). Entomological News 31: 9195.

Nartshuk EP (2012) A check list of the world genera of the family Chloropidae (Diptera, Cyclorrhapha, Muscomorpha). Zootaxa 3267: 1-43.

Nartshuk EP (2014) Grass-fly larvae (Diptera, Chloropidae): Diversity, Habitats, and Feeding Specializations. Entomological Review 94:514-525.Nielsen DW (1990) Arthropod communities associated with Darlingtonia californica. Annals of the Entomological Society of America 83: 189-200.

Sabrosky CW (1965) Family Chloropidae. In: Stone A, Sabrosky CW, Wirth WW, Foote RH, Coulson JR (Eds) A Catalog of the Diptera of America north of Mexico. Agricultural Handbook 276. Agricultural Research Service, United States Department of Agriculture, Washington DC, 773-793.

Szerlip, S. L. 1975. Insect associates (Diptera: Chironomidae, Sphaeroceridae) of Darlingtonia californica (Sarraceniaceae) in California. Pan-Pacific Entomologist 51(2): 169-170. 


\section{Figure captions}

297

298 Figure 1. Aphanotrigonum darlingtoniae, male habitus. A. Dorsal. B. Lateral. Scale bar $=1 \mathrm{~mm}$

299 (photos by J. Mlynarek)

300

301 Figures 2. Aphanotrigonum darlingtoniae, male genitalia. A. Lateral. B. Posterior. C. Ventral.

302 Abbreviations: cer, cerci; epd, epandrium; hyp, hypandrium; phap, phallapodeme; sur, surstylus.

303 Scale bar $=0.1 \mathrm{~mm}$ (drawings by J. Mlynarek)

304

305 Figure 3. 2009 collecting locality of Aphanotrigonum darlingtoniae. Mt Eddy, Siskiyou County,

306 California. (photo by T. Wheeler)

307

308 Figures 4. Tricimba wheeleri, male habitus. A. Dorsal. B. Lateral. Scale bar $=1 \mathrm{~mm}$ (photos by J.

309 Mlynarek)

310

311 Figures 5. Tricimba wheeleri, male genitalia. A. Lateral. B. Posterior. C. Ventral. Scale bar $=$

$3120.1 \mathrm{~mm}$ (drawings by J. Mlynarek)

313

314 Figures 6. A. Tricimba wheeleri, male fore tarsus. B. Tricimba melancholica, male fore tarsus.

315 Scale bars $=0.1 \mathrm{~mm}$ (photos by J. Mlynarek)

316 


\section{Figure 1}

Aphanotrigonum darlingtoniae, male habitus.

A. Dorsal. B. Lateral. Scale bar $=1 \mathrm{~mm}$ (photos by J. Mlynarek) 

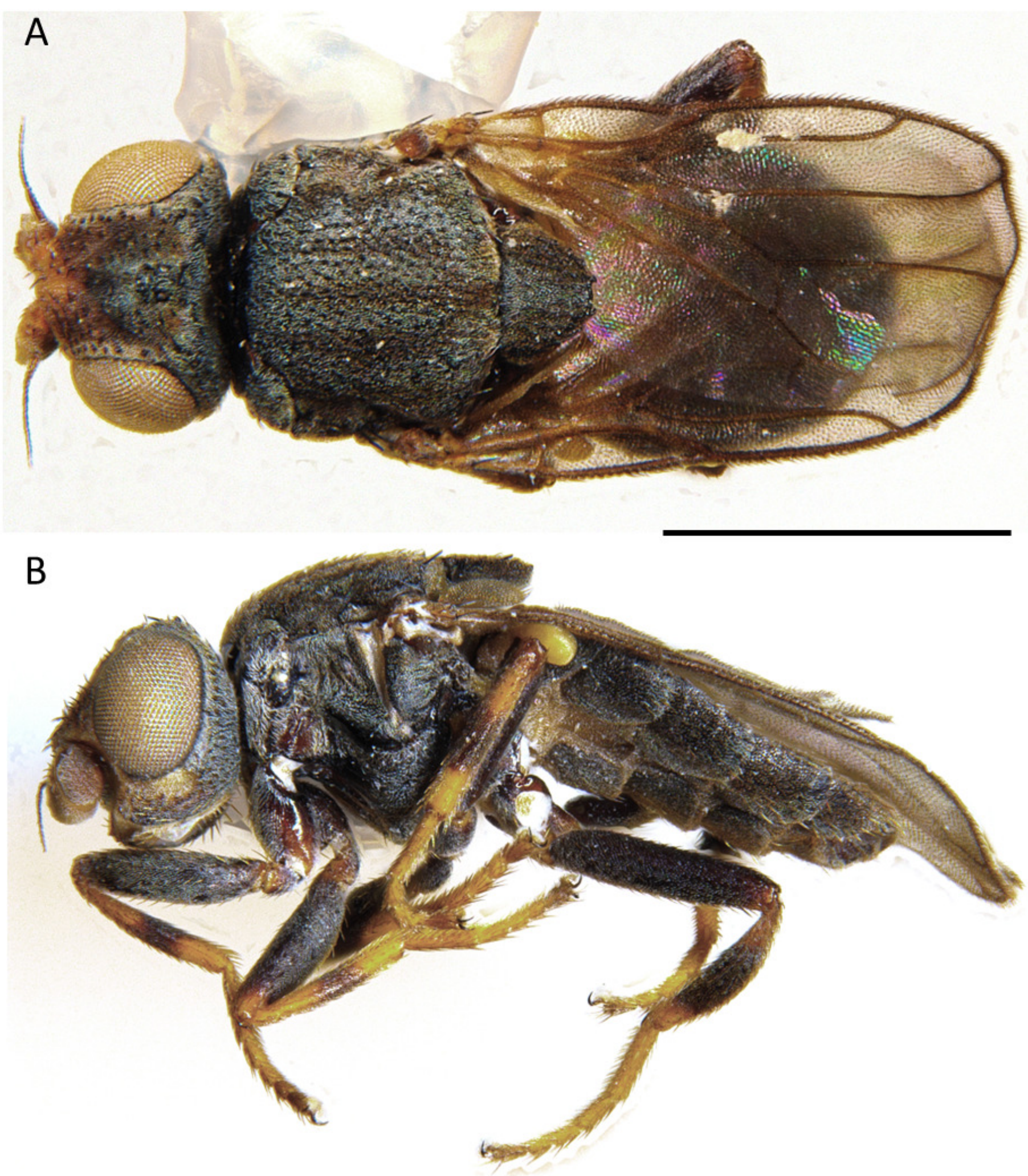
Figure 2

Aphanotrigonum darlingtoniae, male genitalia.

A. Lateral. B. Posterior. C. Ventral. Abbreviations: cer, cerci; epd, epandrium; hyp, hypandrium; phap, phallapodeme; sur, surstylus. Scale bar $=0.1 \mathrm{~mm}$ (drawings by J. Mlynarek)

A

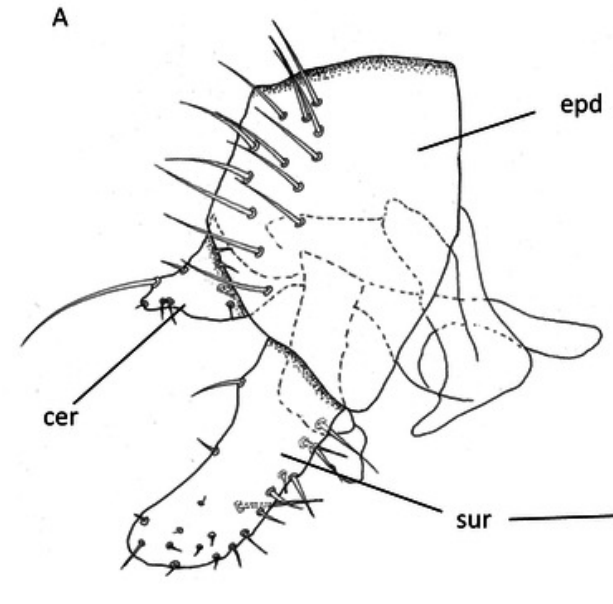

B

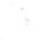

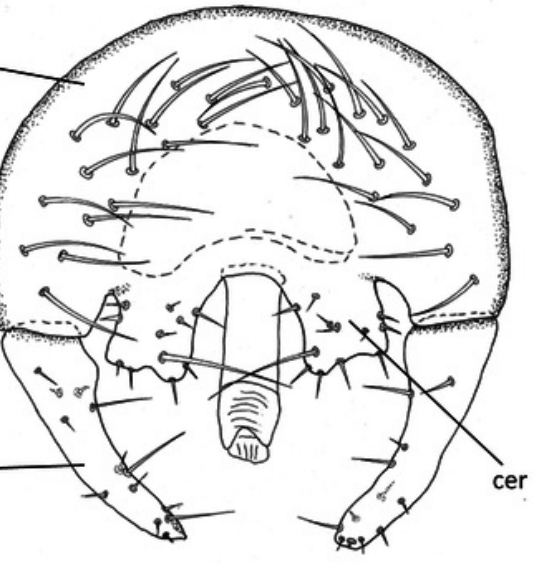

c

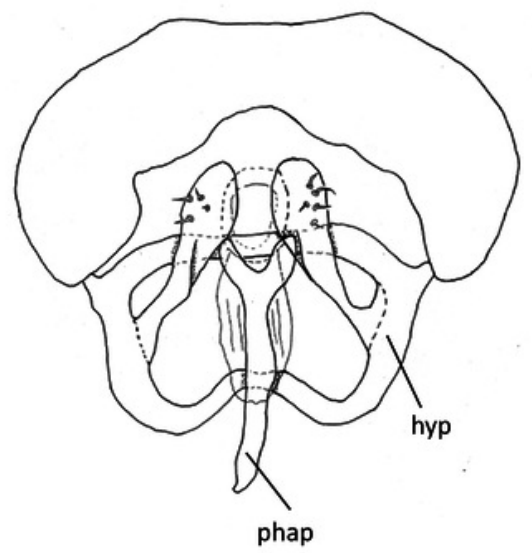


Figure 3

2009 collecting locality of Aphanotrigonum darlingtoniae.Mt Eddy, Siskiyou County, California.

(photo by T. Wheeler)

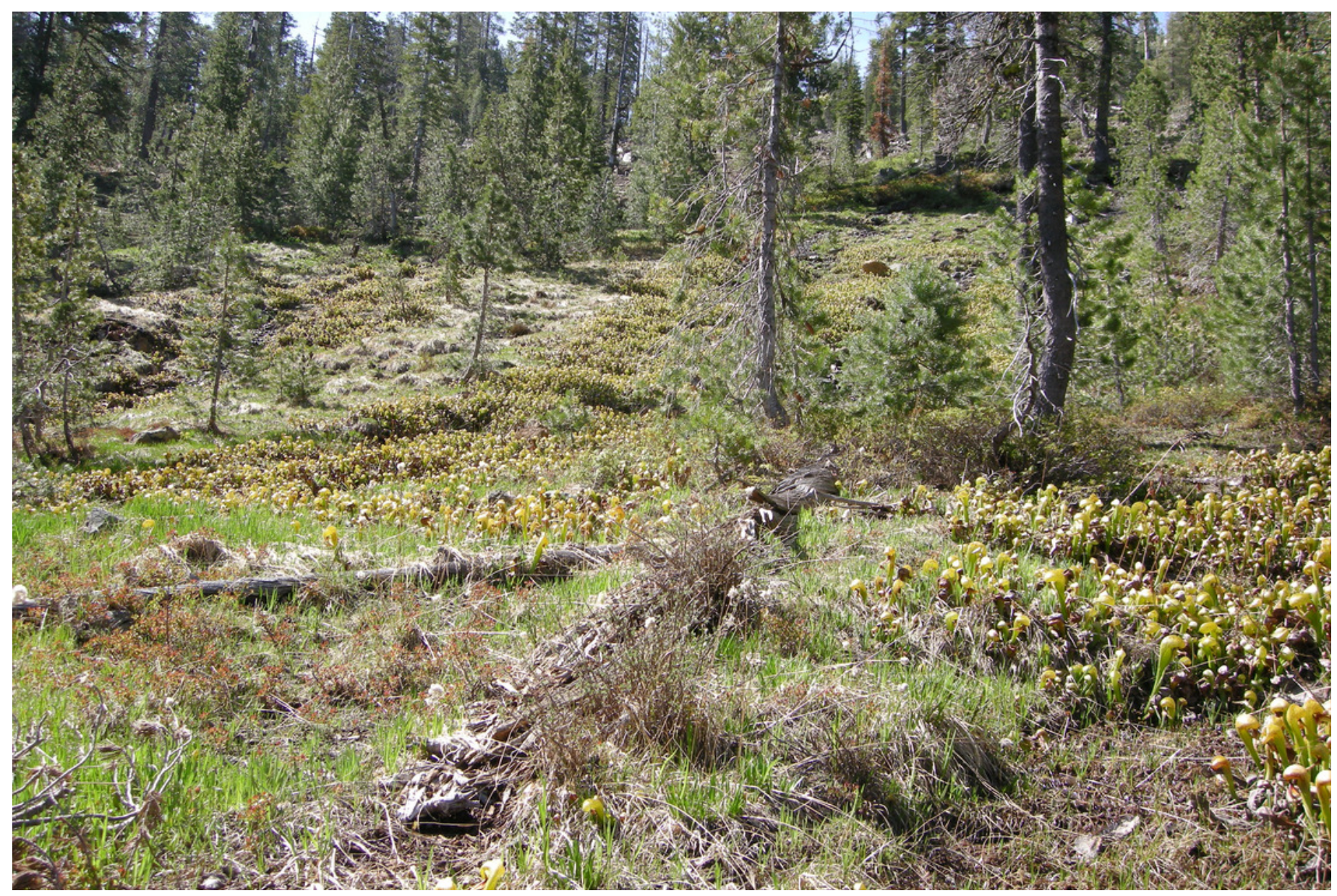


Figure 4

Tricimba wheeleri, male habitus.

A. Dorsal. B. Lateral. Scale bar $=1 \mathrm{~mm}$ (photos by J. Mlynarek) 

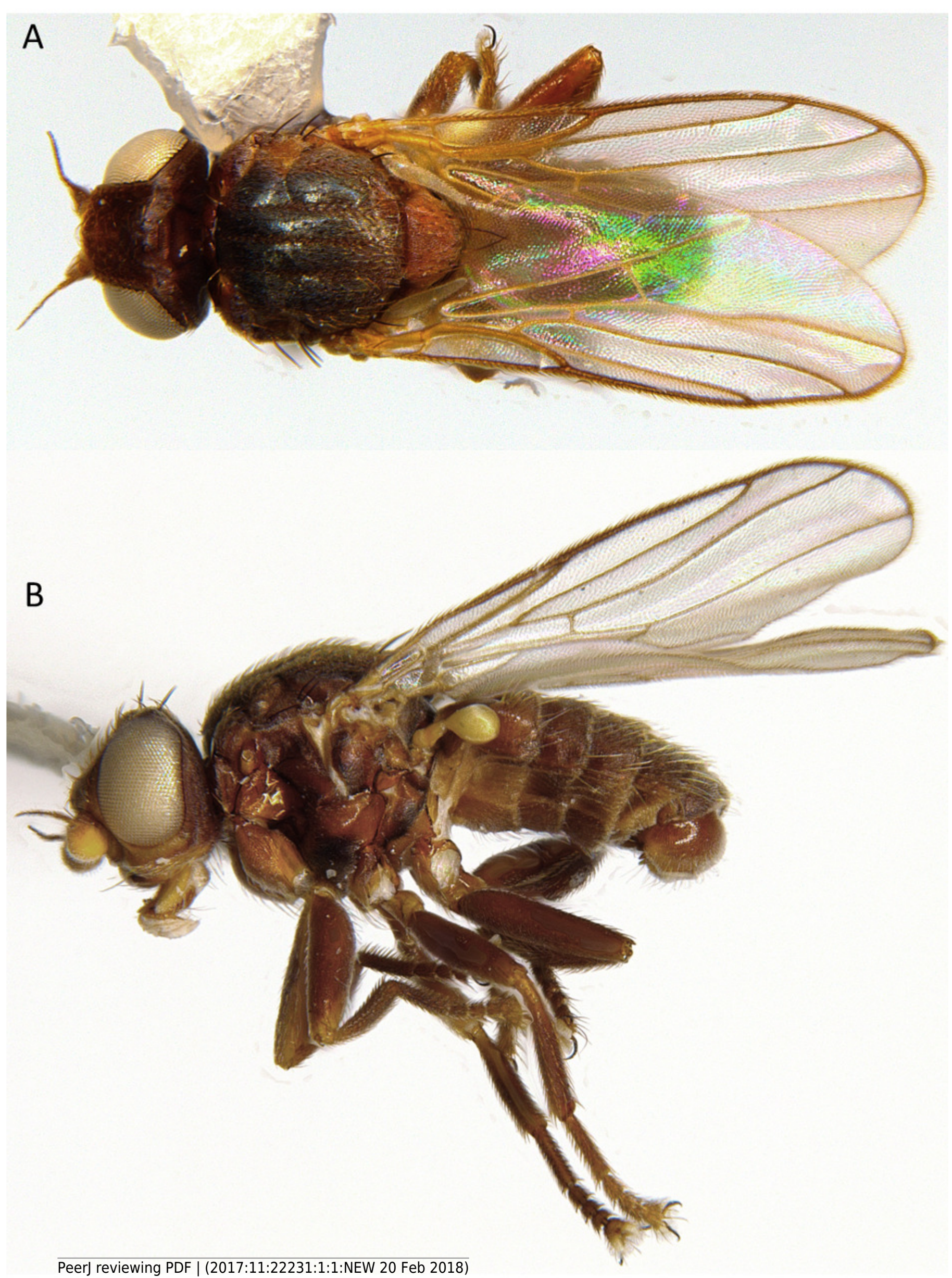
Figure 5

Tricimba wheeleri, male genitalia.

A. Lateral. B. Posterior. C. Ventral. Scale bar $=0.1 \mathrm{~mm}$ (drawings by J. Mlynarek)

A

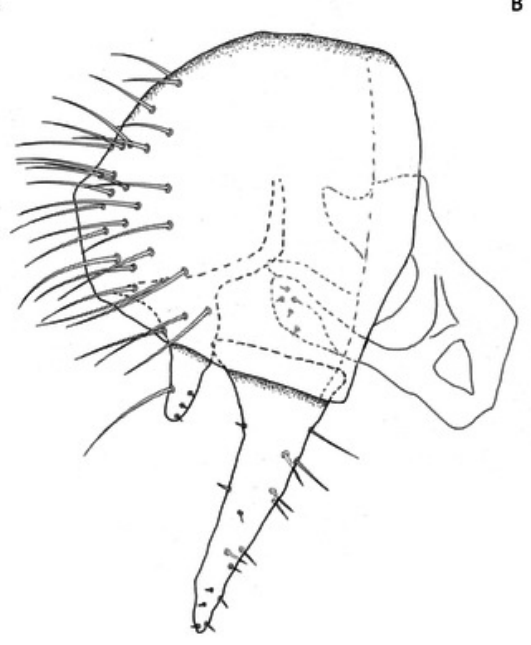

B

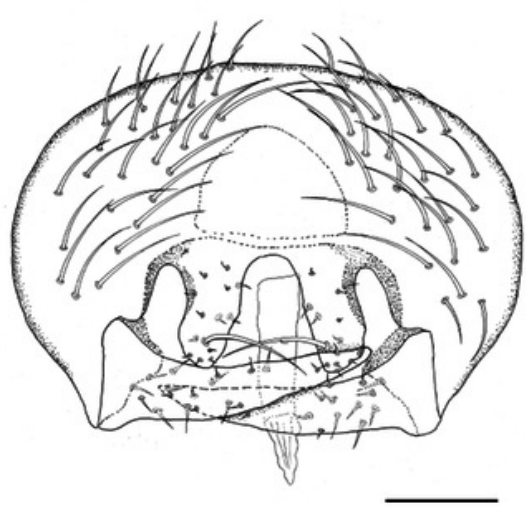

C

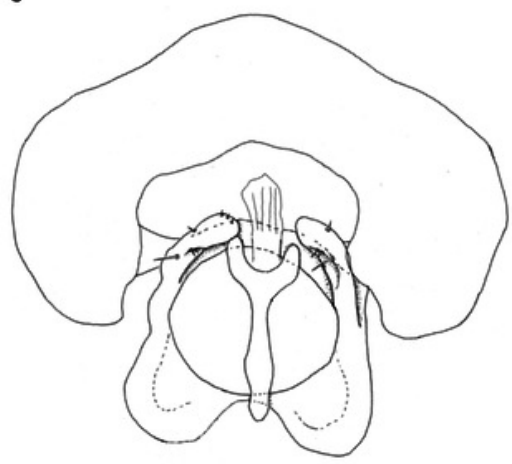




\section{Figure 6}

A. Tricimba wheeleri, male fore tarsus. B. Tricimba melancholica, male fore tarsus.

Scale bars $=0.1 \mathrm{~mm}$ (photos by J. Mlynarek)

A

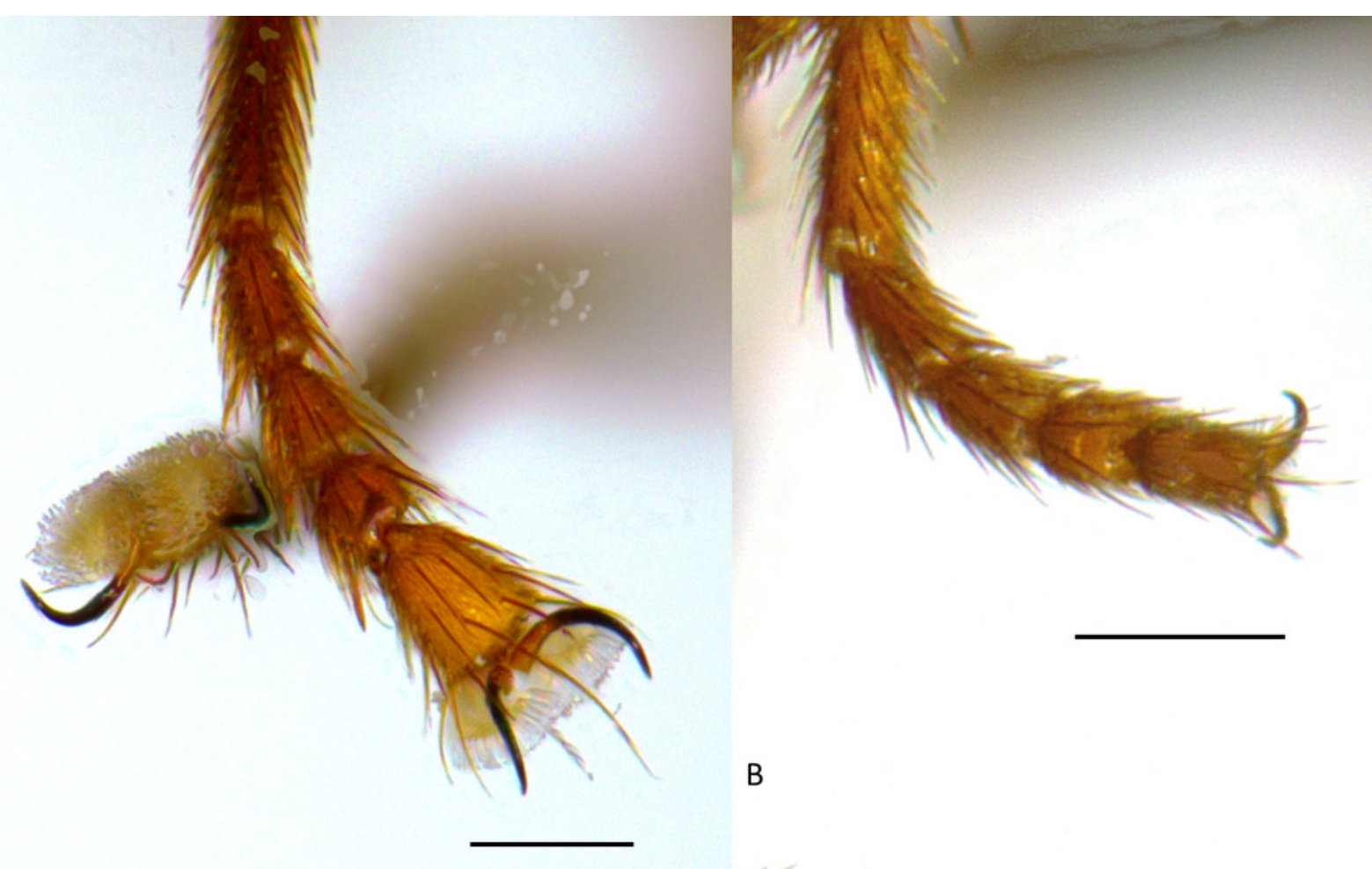

